\title{
PENGANGKATAN PEGAWAI NEGERI SIPIL DALAM JABATAN \\ STRUKTURAL
}

\author{
Nirmala Sari \\ Dosen pada Fakultas Hukum Universitas Muara Bungo \\ e-mail : umb101016@gmail.com
}

\begin{abstract}
Ringkasan
Kedudukan Pegawai Negeri Sipil dalam setiap organisasi pemerintahan mempunyai peranan yang sangat penting, sebab pegawai negeri merupakan tulang punggung pemerintah dalam melaksanakan pembangunan nasional. Untuk dapat mewujudkan penyelenggaraan tugas pemerintahan dan pembangunan dituntut Pegawai Negeri Sipil yang profesional, bertanggung jawab, jujur, dan adil yang dilaksanakan berdasarkan sistem prestasi kerja dan sistem karier. Namun dalam pelaksanaan dan penyelenggaraannya banyak mengalami kesulitan-kesulitan sehingga memerlukan pengaturan yang baik, termasuk dalam proses pengangkatan Pegawai Negeri Sipil untuk menduduki jabatan struktural, karena kedudukan jabatan struktural sangatlah rentan dengan penyimpangan-penyimpangan atau kepentingan pribadi yang mendominasi seperti kepentingan politik, kerabat keluarga dan lain-lain.Penelitian terhadap Pengangkatan Pegawai Negeri Sipil dalam Jabatan Struktural di Kabupaten Bungo dilakukan melalui pendekatan peraturan dan teori yang dihubungkan dengan kenyataan yaitu bagaimana pelaksanaan peraturan kepegawaian di Kabupaten Bungo, yang disebut juga penelitian hukum empiris. Peraturan yang menjadi barometer adalah Peraturan Pemerintah Nomor 100 Tahun 2000 Tentang Pengangkatan Pegawai Negeri Sipil Dalam Jabatan Struktural. Lemahnya aturan hukum yang berkaitan dengan sanksi pelanggaran terhadap pasal 6 Peraturan Pemerintah Nomor 100 tahun 2000 berdampak berkepanjangan dikalangan Pegawai Negeri Sipil itu sendiri, terhadap pelayanan publik serta kinerja Pegawai Negeri Sipil di lingkungan pemerintahan Kabupaten Bungo, antara lain timbulnya sikap apatis dan egosentris bawahan terhadap atasan serta reaksi sosial lainnya, antara lain berupa perilaku yang acuh tak acuh terhadap ugas dan persaingan tidak sehat antar sesama pegawai dan lain-lain yang pada akhirnya menyebabkan Pegawai Negeri Sipil terkotak-kotak secara pikiran.
\end{abstract}

\section{Kata kunci : Pegawai Negeri Sipil, Jabatan Struktural.}

\begin{abstract}
Position of Civil Servants in any government organization has a very important role, because the civil service is the backbone of the government in implementing national development. To be able to realize the implementation of governance and development tasks required of Civil Servants professional, responsible, honest, and fair conducted based systems work performance and career system. But in the execution and implementation experienced many difficulties that require good governance, including in the process of appointment of the Civil Service to structural positions, because the position of the structural position is susceptible to irregularities or personal interests that dominate such political interests, family relatives and etc.Research on the Appointment of Civil Servants in structural positions in Bungo done through regulatory
\end{abstract}


approaches and theories associated with the fact that how the implementation of personnel regulations in Bungo Regency, which is also called empirical legal research. Regulation of the barometer is Government Regulation Number 100 of 2000 on Appointment of Civil Servants in structural positions. Weak rule of law relating to sanction a violation of article 6 of Government Regulation No. 100 of 2000 impacted prolonged among the Civil Service itself, to public services and the performance of Civil Servants in government Bungo, among others, the emergence of apathy and egocentric subordinates to superiors as well as other social reactions, which include behavior indifferent to duties as and unfair competition among fellow employees and others that eventually led to the Civil Service fragmented in mind.

Keywords: Civil Servants; structural positions.

\section{PENDAHULUAN}

Penempatan Pejabat Struktural juga harus sesuai dengan keinginan dan keterampilannya, sehingga gairah kerja dan kedisiplinannya akan lebih baik, serta lebih efektif dalam menunjang terwujudnya tujuan organisasi. Agar hal tersebut dapat tercipta harus ada upaya untuk penataan kembali (right sizing) bidang kepegawaian yang merupakan suatu kebutuhan yang sangat mendesak untuk melihat seberapa jauh kepegawaian ini bisa berperan untuk menciptakan tata pemerintahan yang baik.

Pengangkatan Pegawai Negeri Sipil dalam jabatan struktural seharusnya menggunakan prinsip 'the right man on the right place', namun hasil penelaahan penulis masihterdapat beberapa pengangkatan Pegawai Negeri Sipil dalam jabatan struktural pada Pemerintah Kabupaten Bungo terdapat ada yang tidak mempertimbangkan senioritas dalam kepangkatan, usia, pendidikan dan pelatihan jabatan, dan pengalaman pribadi pegawai negeri sipil, yang merupakan ketentuan yang diatur Pasal 6 Peraturan Pemerintah Nomor 100 Tahun 2000. Sebagai contoh, dalam struktur Satuan Kerja Perangkat Daerah (SKPD), misalnya Badan atau Dinas, dipimpin oleh seorang pejabat eselon II $b$ dengan pangkat Pembina golongan ruang IV/a, Sementara di bawah kepala Badan atau kepala Dinas, ada jabatan Sekretaris dengan eselon IIIa, dengan pangkat III/d, yang merupakan atasan dari para kepala bidang, yang bereselon IIIb dengan pangkat Pembina Tingkat I golongan ruang IV/b. Secara hierarki, sesuai ketentuan Peraturan Pemerintah Nomor 100 Tahun 2000, sudah semestinya, Kepala seharusnya pangkatnya lebih tinggi dari sekretaris, dan sekretaris seharusnya pangkatnya lebih tinggi dari Kepala Bidang yang menjadi bawahannya.

Di lingkungan Pemerintah Kabupaten Bungo, dalam beberapa kali mutasi pejabat didapati Pegawai Negeri Sipil yang sedang menjabat kepala seksi dengan eselon IVa berpangkat Penata, golongan ruang III/c, dipromosikan menduduki jabatan Kepala Bidang dengan eselon IIIb atau jabatan Sekretaris dengan eselon IIIa pada dinas maupun badan. Sementara pegawai negeri sipil yang memangku jabatan yang setingkat kepala seksi dengan pangkat Penata Tingkat I golongan ruang III/d (satu tingkat lebih tinggi dari gol III/c) yang sedang memangku jabatan kepala seksi, tidak dipromosikan memangku jabatan pada eselon yang lebih tinggi.

Penyalahgunaan hukum, aturan, wewenang, dan kekuasaan 
dalam administrasi pemerintah ini memperlemah kontrol sosial akuntabilitas para pejabat pemerintah. Rakyat tidak lagi mampu melakukan akses kepada pejabat untuk meminta ketegasan terhadap hukum. Rakyat tidak berdaya menghadapi aturan yang dibuat oleh administrasi pemerintah dan dipergunakan hanya untuk melindungi kepentingan pejabat sendiri.

\section{Metode Penelitian}

Metode pendekatan penelitiaan yang digunakan dalam penelitian ini adalah metode pendekatan hukum empiris atau yuridis sosiologis (socio legal research), yaitu penelitian terhadap data sekunder dan primer. Melalui pendakatan yuridis sosiologis diteliti kondisi sosial pemerintahan melalui kewenangannya yang diatur oleh ketentuan yang berlaku . Dalam penelitiaan ini terhadap badan hukum diawali dengan menelaah terhadap prinsip atau asas-asas hukum serta substansi hukum berupa kewenangan pemerintah dalam menjalankan roda pemerintahan terutama dalam hal pengangkatan pejabat struktural.

Proses Pengangkatan Pegawai Negeri Sipil Dalam Jabatan Struktural di Kabupaten Bungo.

Setelah melakukan penelitian, diketahui bahwa Pengisian jabatan struktural di Pemerintah Kabupaten Bungo, tidak terlepas dari adanya pertimbangan-pertimbangan lain diluar aturan yuridis formal, termasuk didalamnya pertimbangan kedekatan, kekeluargaan, suku, politik dan lainlain. Masuknya pertimbanganpertimbangan tersebut dapat dilihat pada proses penetapan jabatan struktural mulai dari sosialisasi sampai dengan penetapan hasil sidang Baperjakat.

Berdasarkan penelitian yang penulis lakukan terdapat 30 temuan pengangkatan PNS dalam jabatan struktural, yang pangkat atasannya lebih rendah dari bawahannya (18 temuan pengangkatan PNS dalam jabatan struktural di Dinas-dinas Kabupaten Bungo, 5 temuan pengangkatan PNS dalam jabatan struktural di BadanBadan Kabupaten Bungo, 7 temuan pengangkatan PNS dalam jabatan struktural di Kecamatan-kecamatan di Kabupaten Bungo). Hal tersebut merupakan pelanggaran terhadap Pasal 6 Peraturan Pemerintah Nomor 100 Tahun 2000 Tentang Pengangkatan Pegawai negeri Sipil Dalam Jabatan Struktural diantaranya sebagai berikut;

18 (delapan belas) temuan pengangkatan PNS dalam jabatan struktural di Dinas-dinas Kabupaten Bungo yang pangkat atasannya lebih rendah dari bawahannya ;

1) Kepala Bidang Pendidikan Non Formal di Dinas Pendidikan Ardiman, S.H. diangkat dengan pangkat penata Tingkat I golongan ruang gaji III/d, sementara Kepala Seksi Azra'i, S.Pd berpangkat berpangkat Pembina golongan ruang gaji IV/a. Berarti pangkat Kepala Seksi dengan eselon III.b, lebih tinggi satu tingkat dari pangkat Kepala Bidang yang memegang eselon III.a.

2) Sekretaris Dinas Kesehatan dr. Dini Silvia diangkat dengan pangkat penata Tingkat I golongan ruang gaji III/d, sedangkan Kepala Bidang Pengembangan SDM Kesehatan Muhamad Yusuf, S.KM berpangkat Pembina golongan ruang gaji IV/a. Berarti pangkat Kepala Bidang dengan eselon III.b, lebih tinggi satu tingkat dari pangkat Sekretaris yang memegang eselon III.a. 
3) Kepala Bidang Jaminan Dan Sarana Kesehatan Solikin, S.KM berpangkat penata Tingkat I golongan ruang gaji III/d, sedangkan Kepala Seksi Jaminan Kesehatan Dra. Salmidah, M.PH berpangkat Pembina golongan ruang gaji IV/a. sehingga pangkat Kepala Seksi dengan eselon III.b, lebih tinggi satu tingkat dari pangkat Kepala Bidang yang memegang eselon III.a.

4) Kepala Bidang Kesehatan Syamsuri, A.Ms diangkat dengan pangkat penata golongan ruang gaji III/c, sementara Kepala Seksi Kesehatan Khusus Suhartini, A.MK berpangkat penata Tingkat I golongan ruang gaji III/d. Yang berarti pangkat pejabat eselon IVa lebih tinggi satu tingkat dari pejabat eselon IIIb yang menjadi atasannya.

5) Sekretaris Dinas Sosial, Tenaga Kerja dan Transmigrasi Das'ad Sm.Hk diangkat dengan pangkat penata Tingkat I golongan ruang gaji III/d, sedangkan Kepala Sub Bagian Program Edy Suseno berpangkat Pembina golongan ruang gaji IV/a. sehingga pangkat Kepala Sub Bagian dengan eselon III.b, lebih tinggi satu tingkat dari pangkat Sekretaris yang memegang eselon III.a.

6) Kepala Bidang Hubungan Industri dan Pengupahan Supriadi, S.Ip diangkat dengan pangkat penata golongan ruang gaji III/c, ia menjadi atasan dari dua orang Kepala Seksinya yaitu Arfah Sani, S.Ip Kepala Seksi Hubungan Industrial Organisasi, Pekerja dan Pengusaha, dan Masdong Kepala Seksi
Pengupahan dan Syarat Kerja, Berpangkat Penata Tingkat I Golongan Ruang Gaji III/d, atau setingkat lebih tinggi dari pangkat Kepala Bidangnya.

7) Kepala Dinas Kependudukan dan Pencatatan Sipil H. Djusril Ramli, S.E., diangkat dengan pangkat Pembina golongan ruang gaji IV/a. sementara dua orang bawahannya berpangkat satu tingkat lebih tinggi darinya, yakni Sekretaris Drs. Hasan Effendi, M.Si dan Kepala Bidang Pencatatan Sipil Pitriyati, S.H., yang masingmasing berpangkat Pembina Tingkat I golongan ruang gaji IV/b.

8) Kepala Bidang Pengairan di Dinas Pekerjaan Umum Hasbi Assidiqi, S.T, M.Tech diangkat dengan pangkat pangkat penata golongan ruang gaji III/c, sedangkan Kepala Seksi Operasi dan Pemeliharaan Jaringan Pengairan Jaya Bakti berpangkat penata Tingkat I golongan ruang gaji III/d, sehingga pangkat Kepala Seksi lebih tinggi satu tingkat dari pangkat Kepala Bidang.

9) Sekretaris Dinas Pengelolaan Pasar dan Kebersihan $H$. Muhammad Zen, S.Sos., berpangkat penata Tingkat I golongan ruang gaji $\mathrm{III} / \mathrm{d}$, ia menjadi atasan dari dua orang Kepala Bidangnya yakni Kepala Bidang Kebersihan Halfian Syofyan, SH., dan Kepala Bidang Pertamanan dan Pemakaman Drs. Muhammad Akbar, masing-masing Kepala Bidang tersebut berpangkat Pembina golongan ruang gaji 
IV/a. sehingga pangkat Kepala Bagian dengan eselon III.b, lebih tinggi satu tingkat dari pangkat Sekretaris yang memegang eselon III.a.

10) Kepala Bidang Pengelolaan Pasar Harun Al Rasyid, S.E., diangkat dengan pangkat penata golongan ruang gaji III/c, sementara Kepala Seksi Pengembangan Sumber Daya Pasar Rahmi berpangkat penata Tingkat I golongan ruang gaji III/d. sehingga pangkat Kepala Seksi dengan eselon III.b lebih tinggi satu tingkat dari pangkat Kepala Bidang yang memegang eselon IV.a.

11) Kepala Dinas Kehutanan dan Perkebunan Ishak, S.P., M.M. diangkat dengan pangkat Pembina golongan ruang gaji IV/a. Beliau menjadi atasan dari dua orang Kepala Bidangnya yakni Kepala Bidang yaitu Kepala Bidang Usaha dan Pengembangan Perkebunan Ir. Hj. Sri Argunaini, M.Si dan Kepala Bidang Rehabilitasi Lahan dan Perhutanan Sosial Drs. Muslim. Masing-masing Kepala Bidang tersebut berpangkat Pembina Tingkat I golongan ruang gaji IV/b. sehingga pangkat Kepala Bagian dengan eselon III.a, lebih tinggi satu tingkat dari pangkat Kepala Dinas yang memegang eselon III.b.

12) Sekretaris Dinas Kehutanan dan Perkebunan Amrizal, S.PKP diangkat dengan pangkat Penata Tingkat I golongan ruang gaji III/d, sedangkan ada dua Kepala Bidang yang berada di bawah posisinya yang berpangkat
Pembina Tingkat I yaitu yaitu Kepala Bidang Usaha dan Pengembangan Perkebunan Ir. Hj. Sri Argunaini, M.si, dan Kepala Bidang Rehabilitasi Lahan dan Perhutanan Sosial Drs. Muslim. Masing-masing Kepala Bidang tersebut berpangkat Pembina Tingkat I golongan ruang gaji IV/b. sehingga pangkat Kepala Bagian dengan eselon III.a, lebih tinggi tingkat dari pangkat Sekretaris yang memegang eselon III.b.

13) Kepala Bidang Bina Produksi Kehutanan Dinas Kehutanan dan Perkebunan Hj.Eliza, S.P., M.Si berpangkat penata golongan ruang gaji III/c, sementara Kepala Seksi Perlindungan dan Pengamanan Hutan M. saleh, M.N.S.E. berpangkat Penata Tingkat I golongan ruang gaji III/d. sehingga pangkat Kepala Seksi dengan eselon III.b lebih tinggi satu tingkat dari pangkat Kepala Bidang yang memegang eselon IV.a. berarti pangkat M. Saleh, M.N., S.E. lebih tinggi dari pangkat Hj. Eliza, S.P., M.Si.

14) Sekretaris Badan Dedy Irawan, S.E., M.M. diangkat dengan pangkat Pembina golongan ruang gaji IV/a, sementara Kepala Bidang Ekonomi Ir. Sismilia berpangkat Pembina golongan ruang gaji IV/b. Berarti pangkat pejabat eselon III/b lebih tinggi satu tingkat dari pejabat eselon III/a yang menjadi atasannya.

15) Kepala Bidang Mutasi Drs. H. Ansori dilantik dengan pangkat penata golongan ruang gaji III/c, sementara kepala bidang 
Promosi dan Penempatan Sri Bintan berpangkat Penata golongan ruang gaji III/d, yang berarti pangkat pejabat eselon IVa lebih tinggi satu tingkat dari pejabat eselon IIIb yang menjadi atasannya.

16) Sekretaris

Badan

Penanggulangan

Bencana

Daerah, Kesatuan bangsa, Politik dan Linmas Drs. Suprianto, diangkat dengan pangkat Pembina golongan ruang gaji IV/a, sementara Kepala Bidang Pencegahan Dan Kearsipan Usman Gumanti, S.H., berpangkat Pembina tingkat 1 golongan ruang gaji IV/b, yang berarti pangkat Kepala Bidang Usman Gumanti, S.H. dengan eselon III.b lebih tinggi satu tingkat dari pangkat atasannya, Sekretaris Badan Penanggulangan Bencana Daerah, Kesatuan bangsa, Politik dan Linmas pejabat structural dengan eselon III.a.

17) Kepala Bidang Kedaruratan dan Logistik jasrul, S.Sos., diangkat dengan pangkat panata golongan ruang gaji III/c di Badan Penanggulangan Bencana Daerah, Kesatuan bangsa, Politik dan Linmas, sementara Kepala Sub Bidang logistik Yan Pertana, S.T berpangkat penata Tk.1 golongan ruang gaji III/d, berarti pangkat Kepala Bidang dengan eselon III/b, lebih tinggi satu tingkat dari pangkat Kepala Bidang yang memegang eselon IV/a.

18) Kepala Bidang Kelembagaan Dan Sarana Prasarana Nasrun, S.E., diangkat dengan pangkat Penata golongan ruang gaji III/c, sementara Kepala Sub Bidang kelembagaan Saharman, SP berpangkat Pembina golongan ruang gaji IV/a, sehingga pangkat Saharman, SP sebagai Kepala Sub Bidang dengan eselon III/a lebih tinggi dua tingkat dari pangkat Kepala Bidang yang memegang eselon IV/a.

7 temuan pengangkatan PNS dalam jabatan struktural di Kecamatankecamatan di Kabupaten Bungo yang pangkat atasannya lebih rendah dari bawahannya ; :

1) Camat Pasar Muara Bungo Fahmi, S.Ag, M.E. diangkat dengan pangkat Pembina golongan ruang gaji IV/a, sementara Abrizal, S,Sos, M.Si berpangkat Pembina Tingkat I golongan ruang gaji IV/b menjadi Sekretaris Camat Pasar Muara Bungo yang menjadi bawahan langsung Camat. Pangkat Abrizal, S, Sos, M.Si sebagai bawahan lebih tinggi satu tingkat dari pangkat Camat di Kecamatan Pasar Muara Bungo tersebut.

2) Sekretaris Camat Bungo Dani Putra Buana, S.Sos diangkat menjadi Sekretaris Camat Bungo Dani dengan pangkat Penata golongan ruang gaji III/c, sementara Amran, BBA, S.Sos

3) Kepala Seksi Ketentraman Dan Ketertiban Umum di lingkungan kecamatan bungo dani tersebut berpangkat penata Tingkat I golongan ruang gaji III/d, sehingga pangkat pejabat struktural Kepala Seksi lebih tinggi satu tingkat dari Sekretaris Camat.

4) Sekretaris Camat Pelepat Ilir Suratman, A.Md dilantik dengan 
pangkat Penata golongan ruang gaji III/c, sedangkan kepala seksi Ir. Redno Barusdi, pada Kecamatan tersebut berpangkat Pembina golongan ruang gaji IV/a berarti pangkat Ir. Redno Barusdi dua tingkat lebih tinggi dari pangkat Suratman, A.Md.

5) Camat Muko-Muko Bathin VII Zamroni, S.Ag, diangkat dengan pangkat Penata golongan ruang gaji III/d, sementara sekretaris di Kecamatan tersebut Drs. Kaharudin berpangkat Pembina golongan ruang gaji IV/b, sehingga pangkat Drs. Kaharudin sebagai bawahan lebih tinggi dua tingkat dari pangkat atasannya.

6) Sekretaris Camat di Kecamatan Rantau pandan M.Yusuf, S.Pdi diangkat menjadi Sekretaris Camat di Kecamatan tersebut dengan pangkat Penata golongan ruang gaji III/c, sedangkan $\mathrm{H}$. Bahman yang berpangkat Penata Tk 1 golongan ruang gaji III/d sebagai Kepala Seksi Perekonomian, sehingga pangkat jabatan struktural $\mathrm{H}$. Bahman lebih tinggi satu tingkat dari pangkat Sekretaris di Kecamatan tersebut.

7) Sekretaris camat di kecamatan Jujuhan Muhammad Zadjius, S.H., berpangkat Penata golongan ruang gaji III/C secara struktural berada lebih tinggi posisinya dari dua orang Kepala Seksi yaitu Kepala Seksi Tata Pemerintahan Aripin Saad dan Kepala Seksi Ketentraman dan Ketertiban Umum H. Alwi, S.Pd., masing-masing Kepala Seksi tersebut berpangkat Penata golongan ruang gaji III/d, sehingga secara kepangkatan Sekretaris di kecamatan Jujuhan lebih rendah dari pangkat Kepala Seksinya.

Dari temuan pelanggaran sebanyak 30 (tiga puluh) kasus tersebut diatas Kepala Badan Kepegawaian Daerah Kabupaten Bungo H. Bakhtiar, S.E., M.Si menyatakan bahwa penempatan posisi pejabat yang pangkatnya lebih rendah dari pejabat yang ada di bawahnya diakui mengenyampingkan Peraturan pemerintah Nomor 100 tahun 2000 tentang Pengangkatan Pegawai Negeri sipil Dalam jabatan Struktural, terutama Pasal 6, tetapi yang menjadi faktor penentu Pemerintah Kabupaten Bungo dalam menempatkan pegawai Negeri Sipil adalah berdasarkan dengan pola kerja dari PNS yang bersangkutan.

Faktor Yang Mempengaruhi Pengangkatan Pegawai Negeri Sipil Dalam Jabatan Struktural Di Kabupaten Bungo

Faktor-faktor yang mempengaruhi Pengangkatan Pegawai Negeri Sipil Dalam Jabatan Struktural Di Kabupaten Bungo antara lain yaitu:

Pemahaman otonomi daerah yang salah, Pemerintah Daerah mengartikan otonomi daerah dalam artian Pemerintah Daerah berhak menyelenggarakan rumah tangganya sendiri dalam perspektif hak yang dimiliki itu adalah hak mutlak, sehingga hak yang melekat tersebut kemudian diartikan sebagai suatu kewenangan yang seluas-luasnya dan kemudian mengakibatkan kebanyakan dari pejabat- pejabat daerah menilai bahwa yang berhak untuk mengisi jabatan struktural adalah putra asli daerah, bukanlah pendatang dari luar daerah tersebut. Sehingga hal ini mengakibatkan jabatan struktural diisi oleh orang-orang yang tidak memenuhi 
kompetensi atau sebagaimana yang diatur oleh Peraturan Pemerintah Nomor 100 tahun 2000 tentang npengangkatan Pegawai Negeri Sipil Dalam Jabatan Struktural. Artinya walaupun pegawai negeri sipil tersebut pangkatnya belum layak untuk menduduki jabatan struktural, namun dikarenakan putra asli daerah maka pegawai tersebut diberikan kesempatan untuk menduduki jabatan struktural.

Pemilukada secara langsung yang mengakibatkan kepala daerah memiliki kewenangan yang sangat besar (layaknya raja-raja kecil yang berada di daerah) sehingga untuk mengisi jabatan struktural kewenangannya mutlak berada ditangan kepala daerah.Kepala Daerah/Pemerintah Daerah dalam mengangkat pejabat struktural cendrung memilih orang-orang yang gampang diajak bekerjasama dengan pemerintah daerah.Ada indikasi politik balas budi dari Kepala Daerah terpilih terhadap tim sukses. Karena tidak sedikit dari tim sukses itu berasal dari golongan Pegawai Negeri Sipil.Kepangkatan dan latar belakang pendidikan di nilai tidak menjamin mutu dan kualitas kerja seseoang pegawai negeri sipil yang akan menjabat jabatan struktural untuk bekerja lebih baik.Kepala daerah tidak memiliki integritas yang tinggi terhadap komitmen untuk menjalankan tugasnya sebagai kepala daerah, namun lebih cendrung mengikuti keinginan pihak-pihak (tim sukses) untuk campur tangan dalam birokrasi pemerintahan daerah.Tidak adanya sanksi yang benarbenar nyata yang memberikan efek jera terhadap pelanggara-pelanggaran tersebut. Karena banyak kasus pelanggaran yang terjadi tidak dilaporkan kepada lembaga yang berwenang, walaupun kasus tersebut dapat di PTUN kan.

\section{Akibat Hukum Pengangkatan Pegawai Negeri Sipil Dalam Jabatan Struktural Yang Bertentangan Dengan Peraturan Perundang- undangan Yang Berlaku.}

Lemahnya aturan hukum yang berkaitan dengan sanksi pelanggaran terhadap pasal 6 Peraturan Pemerintah Nomor 100 Tahun 2000, berdampak berkepanjangan dikalangan Pegawai Negeri Sipil itu sendiri, terhadap pelayanan publik serta kinerja Pegawai Negeri Sipil di lingkungan Pemerintah Kabupaten Bungo, berikut ini adalah akumulasi hasil wawancara penulis dengan berbagai sumber antara lain:

Terciptanya sikap apatis dan tidak disiplinnya Pegawai Negeri Sipil dalam bekerja, tidak mau berinovasi, muncul sikap malas-malasan karena masa depan karir tidak pasti dan ukuran prestasi kerja yang tidak jelas.

Terganggunya sistem kerja pada satuan kerja perangkat daerah karena munculnya egosentris seorang PNS yang senior enggan diperintah oleh atasannya yang berpangkat rendah sehingga tidak menghormati/menghargai dan tidak loyal terhadap pimpinan.

Mekanisme dalam penilaian kinerja pegawai tidak berjalan sebagaimana mestinyakarena pangkat pejabat yang memimpin lebih rendah dari bawahan.

Pelayan publik menjadi tidak maksimal karena Pegawai Negeri Sipil bekerja tidak profesional, bekerja hanya karena perintah atasan, dan cenderung memenuhi kepentingan sesaat (pragmatis).

Terkotak-kotaknya kalangan Pegawai negeri sipil, yaitu dibarisan yang netral, barisan yang pro dan kontra terhadap Bupati/wakil bupati terpilih.Terjadinya "Tsunami Politik" yang mematikan karir Pegawai negeri sipil yang berprestasi namun tidak 
menjadi pendukung Bupati/ Wakil Bupati terpilih.Bupati stress karena tidak dapat melaksanakan tugas dengan baik akibat dari koordinasi tidak efektif dengan bawahannya.Berbagai Akibat yang tertera diatas adalah ungkapan rasa dari berbagai kalangan pejabat dan staf di sebagian SKPD di Pemerintah Kabupaten Bungo, sehingga pelaksanaan pekerjaan boleh dikatakan asal selesai saja dengatn baik, tanpa memikirkan kualitas maksimal yang perlu dicapai.

\section{Kesimpulan}

Berdasarkan pembahasan yang telah dilakukan, dapat diambil kesimpulan sebagai berikut :

Pelaksanaan pengangkatan

Pejabat struktural di Kabupaten Bungo, belum mengikuti ketentuan yang disyaratkan Peraturan Pemerintah Nomor 100 Tahun 2000 Tentang Pengangkatan Pegawai Negeri Sipil Dalam Jabatan Struktural karena ditemui adanya pengangkatan pejabat struktural yang mengabaikan Pasal 6 tentang senioritas dalam kepangkatan, usia, pendidikan dan pelatihan jabatan serta pengalaman pribadi pegawai negeri sipil.

Faktor-faktor yang mempengaruhi pengangkatan Pegawai Negeri Sipil dalam Jabatan Struktural di Kabupaten Bungo yang paling dominan dirasakan adalah desakan tim sukses yang merasa berbudi sebagai pendukung dan berhasil menghantarkan Bupati / wakil bupati sebagai Bupati / wakil bupati terpilih, fungsionaris dari partai politik yang mengusung calon bupati / wakil bupati dan tokoh masyarakat lainnya yang berpengaruh di Kabupaten Bungo maupun sanak keluarga, serta pejabat struktural instansi pemerintahan di tingkat yang lebih tinggi.

Akibat hukum pengangkatan Pegawai Negeri Sipil dalam Jabatan
Struktural yang bertentangan dengan Peraturan Perundang-undangan yang berlaku di Kabupaten Bungo tidak ada sanksi yang benar-benar nyata yang memberikan efek jera. hanya jika ada PNS yang menuntut dan memenangkan tuntutan di PTUN maka Keputusan PTUN hanya mengembalikan PNS yang dicopot tersebut kembali menduduki jabatannya semula.

Namun dalam lingkungan Pemerintah Kabupaten Bungo akibat tersebut menciptakan sikap apatis dan tidak disiplinnya Pegawai Negeri Sipil dalam bekerja, Terganggunya sistem kerja pada satuan kerja perangkat daerah karena munculnya egosentris seorang PNS yang senior, Mekanisme dalam penilaian kinerja pegawai tidak berjalan, Pelayan publik menjadi tidak maksimal karena Pegawai Negeri Sipil bekerja tidak profesional, Terkotakkotaknya kalangan Pegawai negeri sipil, Terjadinya

"Tsunami Politik" yang mematikan karir Pegawai negeri sipil yang berprestasi namun tidak menjadi pendukung Bupati/ Wakil Bupati terpilih, Bupati stress karena tidak tidak dapat melaksanakan tugas dengan baik akibat dari koordinasi tidak efektif antara bawahan.

\section{Saran}

Berdasarkan hasil penelitian di atas, penulis menyarankan hal-hal sebagai berikut :

Diharapkan Pemerintah daerah menetapkan Peraturan yang mengatur tentang Standar baku terhadap Pegawai Negeri Sipil yang dapat diusulkan untuk dipromosikan dari staf ke jabatan struktural terendah dan peningkatan eselon ke tingkat yang lebih yang tetap berpedoman kepada Peraturan Pemerintah Nomor 100 Tahun 2000 Tentang Pengangkatan Pegawai Negeri 
Sipil Dalam Jabatan Struktural sebagaimana telah diubah dengan Peraturan Pemerintah Nomor 13 Tahun 2002.

Pada masa yang akan datang diharapkan, ada penerapan sanksi yang tegas dan nyata terhadap Pegawai Negeri Sipil yang menjadi Tim Sukses bakal calon kepala daerah, karena akan mengganggu karir pegawai yang bersangkutan dan pegawai lainnya di masa mendatang.

Tim BAPERJAKAT tidak diperbolehkan memberikan rekomendasi pengusulan pengangkatan Pegawai Negeri Sipil di luar ketentuan dan peraturan perundang-undangan yang berlaku.

Adanya penerapan sanksi hukum yang nyata akibat dari tindakan pelanggaran terhadap Peraturan Pemerintah Nomor 100 Tahun 2000 Tentang Pengangkatan Pegawai Negeri Sipil Dalam Jabatan Struktural yang dilakukan oleh Pemerintah Daerah dalam melaksanakan pengangkatan Pegawai Negeri Sipil Dalam Jabatan Struktural di Kabupaten Bungo.

Bagi Pegawai Negeri Sipil di lingkungan Kabupaten Bungo yang mengalami akibat dari pelanggaran Pasal 6 yang dilakukan Pejabat Pembina Kepegawaian daerah Kabupaten Bungo agar melaporkan dan menggugat keputusan Pejabat Pembina Kepegawaian daerah Kabupaten Bungo yang nyata-nyata cacat secara hukum tersebut ke PTUN agar pejabat Pembina kepegawaian daerah mendapatkan efek jera dari perbuatannya yang mengabaikan Peraturan Pemerintah dan agar para Pegawai Negeri Sipil mendapatkan rasa keadilan sebagaimana mestinya.

\section{DAFTAR PUSTAKA}

\section{A. Buku- buku :}

Jimly Asshiddiqi, Konstitusi dan Konstitusionalisme Indonesia, Jakarta, 2004.

J.Kaloh, Mencari Bentuk Otonomi Daerah, Suatu Solusi Dalam Menjawab Kebutuhan lokal Dari Tantangan Global, Renika Cipta, Jakarta, 2002.

Miriam Budiardjo, Dasar-dasar ilmu politik, gramedia pustaka utama, Jakarta, 1998

MiftahToha, Manajemen Kepegawaian Sipil di Indonesia. Kencana Prenada Media Group, Jakarta, 2008.

Muhammad Kusnardi dan Harmaily Ibrahim, Pengantar Hukum Tata Negara Indonesia, (PSHTN FH UI) dan Sinar Bakti, Jakarta, 1988.

Moh. Mahfud MD, Hukum Kepegawaian Indonesia, Liberty Yogyakarta 1988.

Philipus M Hadjon, Etal, Pengantar Hukum Administrasi Indonesia, Gadjah Mada University, Yogyakarta, 2005.

Satjipto Rahardjo, Ilmu Hukum, PT. Citra aditya Bakti, Bandung 2000.

Sedarmayanti, Sumber Daya Manusia dan Produktivitas Kerja, Mandar Maju, Bandung, 2001.

Soerjono Soekanto, Metode Penelitian Hukum, Rineke Cipta, Jakarta.

\section{B. Peraturan Perundang-Undangan :}

Undang-Undang Nomor 08 Tahun 1974

Tentang Pokok-pokok Kepegawaian.

Undang-Undang Nomor 43 Tahun 1999

Tentang Pokok-pokok Kepegawaian.

Peraturan Pemerintah Nomor 100

Tahun 2000 Tentang Pengangkatan Pegawai Negeri Sipil Dalam Jabatan Struktural. 
Peraturan Pemerintah Nomor 13 Tahun 2002, Tentang Perubahan Atas Peraturan. Pemerintah Nomor 100
Tahun 2000 Tentang Pengangkatan Pegawai Negeri Sipil Dalam Jabatan Struktural. 